\title{
Developing Language Literacy in the Educational Scene $^{1}$
}

\author{
Judit Pazonyi-Edit Bodonyi*
}

\begin{abstract}
The empirical research the paper is based on was carried out in forms of workshops organized for groups of international teacher trainees between 2009 and 2012. The aim of these workshops was to master a "learning by doing" experiential model by which language literacy can be effectively developed or improved.

The topic is discussed in its complexity, highlighting some important issues of teacher training internationally, and also the still controversial situation of alternative education that tailors its curriculum to the pupils and students' needs and facilitates such methods as the one the paper details on.
\end{abstract}

Key words: literacy, functional illiteracy, drama in the classroom, teacher training, alternative schools.

\section{Situation in Europe}

"Mother, you had me but I never had you"2: John Lennon's well known lyrics is whispered together with the Hungarian poet's lines: "She just, giving me no look or thrashing,/Went on, and in silence spread out the washing"3. Students are

\footnotetext{
* Judit Pazonyi, Institute of Behavioural Siences and Communication Theory, Corvinus University of Budapest, Hungary; judit.pazonyi@uni-corvinus.hu

Edit Bodonyi, Karoli Gaspar University of the Reformed Church in Hungary, Budapest, Hungary; bodonyi.edit@kre.hu

${ }^{1}$ The article is a revised and extended version of a paper written for a workshop on the CLIL method (see:

https://www.google.sk/search?q=inauthentic\&rlz=1C1CHMO_skSK506SK506\&oq=ina uthentic\&aqs=chrome..69i57j015.2655j0j9\&sourceid=chrome \&espv=210\&es_sm=93\&i $\mathrm{e}=\mathrm{UTF}-$

8\#es_sm $=93 \&$ espv $=210 \& q=\% 22$ influenced $+b y+$ the + traditional+nursery+rhymes $\% 22$ )

${ }^{2}$ Mother by John Lenon

${ }^{3}$ Mother by Attila József
} 
trying to catch and touch and embrace a person, but her face is covered and she is always turning her back towards them. At the same time a male voice can be heard: "Bind us together / with a lock of your hair"4. Now the students form a wide circle. A man is trying to get inside. He has been refused several times, but all of a sudden somebody takes him to the very middle of the circle. The others are getting closer and closer as if protecting him against all dangers. Now female voices start reciting: "I am becoming my mother", and the crowd of students now forms a circle again in which the young man and a young woman are embracing each other in the middle.

The white paper curtains of a small, $90 \mathrm{~cm} \times 60 \mathrm{~cm} \times 50 \mathrm{~cm}$ size theatre rise. First only the rhythm of marching is heard, then suddenly the two-dimensional, tiny paper puppets of Christopher Robin and that of Alice's appear on the stage. They are watching the changing of the guards at Buckingham Palace with their backs towards the audience. The guards start to come to the stage one after the other, in pairs. They grow in size to present that they are coming nearer and nearer. Simultaneously, reciting A. A. Milne's poem, Buckingham Palace can be heard.

The dramatic scenes above are from workshops organized for both Hungarian and international groups of early-, primary and secondary education teachertrainees in Hungary and in countries, such as Austria, Spain, Britain and Belgium in the last few years. The participants of the workshops presented their interpretations of the poems through acting, transforming feelings and ideas into actions. The presented and practised method raises questions not only about itself but about education and teacher training. Besides detailing on the method, the other aim of this paper is to discuss some of these issues.

It is only Austria among the above mentioned countries where "Drama Education" course is compulsory in one term for early- and primary education teacher-trainees. In the other countries (Spain, Britain and Belgium, and also Norway from where students took part in the workshops in Hungary), there is no drama education in the curriculum for students studying to become early- and primary education teachers. No wonder that at the beginning of the workshop, before trying to follow the method that is detailed below, one student remarked: "This is Chinese to me." In Britain, many teacher trainees take up drama courses, and there is a lot of research into the connections between English and Drama $^{6}$, but the latter is not integrated into the training. Still for British students

\footnotetext{
${ }^{4}$ My mother by Mahmoud Darvish

${ }^{5}$ I am Becoming my Mother by Lorna Goodison

${ }^{6}$ Last conference on "A dramatic-inquiry approach to teaching and learning" was organised by IoE London University, on 8th February 2013.; also see FLEMING, M., Christine MERREL, C. and TYMMS, P., The Impact on Pupils' Language,
} 
the workshop felt familiar. In spite of lacking drama experiences, most students found this experiential, creative, and multisensory method useful and interesting in developing the cognitive behaviour of young - and even secondary school children through working with nursery rhymes and other poems. These students from Belgium, Norway, Austria, the Netherlands, Spain and Hungary all agreed that they would love to learn more about similar approaches within the frame of their training to become teachers?

\section{Functional Illiteracy}

For the last three decades, the term of functional illiteracy has been widely discussed, but an in-depth research of the phenomenon is still a long way to go. It is only recently that the Telegraph has come out with again two articles on the topic ${ }^{8}$ discussing the danger spreading in the English speaking world, in Australia and in Britain, but naturally the thorough investigation of the social, psychological, cognitive, and technical reasons is missing from these articles. The authors of this paper have no room here to find out about these reasons behind the problem either, but will offer methods that can develop imagination through which literacy could be improved, and try to call attention to those educational scenes where these methods might be available for children.

In Europe, the poor results of many EU countries of the PISA 2000 survey (Programme for International Student Assessment organized by the OECD), and those that followed it in 2003, 2006, and 2009, in which more than 40 countries were investigated, caught the attention to the phenomenon of functional literacy, the dangerous consequences of which shocked everybody interested in education, including experts.

Mathematics, and Attitude in two Primary Schools. Research in Drama Education: The Journal of Applied Theatre and Performance, 2(4), 177-197.; Research in Drama Education: The Journal of Applied Theatre and Performance, 2012, 17(1). , also: FRANKS, A. Drama in teaching and learning language and literacy. In: WYSE, D., ANDREWS, R. and HOFFMAN, J., eds., The Routledge international handbook of English language and literacy teaching Routledge. 2010.

${ }^{7}$ Being a lecturer of Methodology of Teaching English to Young Children in a primary teacher training college, I was trying to find different ways of developing literacy in childhood, but in the curriculum there was little room for experimental methods, therefore mostly international workshops provided the scenes for them. (Pazonyi, J.)

8 http://www.telegraph.co.uk/education/educationnews/9283222/Graphic-UK-childrenmore-likely-to-be-illiterate-than-Australian-or-Canadian-children-despite-higher-

spending.html,

http://blogs.telegraph.co.uk/news/edwest/100160058/one-in-five-brits-are-functionallyilliterate-and-public-schoolboys-like-nick-clegg-will-keep-it-that-way/ [viewed 30 July 2013]. 
Among other objectives, the aim of PISA 2000 survey was to assess 15-year-old children's reading comprehension, and it turned out that approximately one half of the teenage population of the world have major problems in understanding reading. Isabel L. Beck and Connie Juel argue that "Early attainment of decoding skill is important because this early skill accurately predicts later skill in reading comprehension. There is strong and persuasive evidence that children who get off to a slow start rarely become strong readers (Stanovich, 1986). Early learning of the code leads to wider reading habits both in and out of school (Juel, 1988)." " It can be added that although Krashen's silent period hypothesis (cf. Krashen, 1988) can also be applied to some extent for starting learning to read, facilitating reading (i.e. creating possibilities for it without any pressure to carry out the task) by developing children's imagination through story-telling, involving them in different actions, and also providing children with texts and pictures to cater the visual types, should be done from as early as possible, maybe even from the last year of pre-schools.

"Learning by doing" methods have been widely accepted in early - and primary education with their multisensory approaches for the last two decades. On the other hand, transforming reading experiences into drama activities by forming the text into two- or three-dimensional images (paper theatre, acting) is done only when there is a plot (a story) that can be rewritten into a dramatic text, however, lyrical poems are hardly ever acted out though imagination and thus literacy could be effectively developed by doing so.

At pre-school age, children's imagination is very powerful, but their experiences are relatively underdeveloped. When the pre-operational stage (cf. Piaget, 1997) is over at around the age of 6 , growing experience increasingly takes over the role of the imagination. At this age, a child can already clearly distinguish between fantasies and reality, although the inter-changeability between the two spheres is still very easy for them. In Hungarian schools, teachers - with the aim of preparing children for the formal operational stage (this Piaget-coined term refers to the last developmental period from age 12 to adulthood) - mostly ignore the fact that lower-primary school children have difficulties in operating deductive logic, thereby forcing young children to explain most phenomena that come up at school and to use abstract concepts, such as grammatical or mathematical terms, instead of focusing on creative tasks involving children's imagination (cf. Piaget, 1997) may result in unnecessary stress, which can easily lead to learning problems.

Reading is a complex physical, cognitive, psychological and linguistic skill in which a balanced combination of language skills, memory, concentration and perception operate at the same time, thus creating the knowledge of decoding

${ }^{9}$ BECK, I. L.and JUEL, C. The Role of Decoding in Learning to Read: a professional paper. In.: Scholastic Red [online]. [viewed 31 July 2013]. Available from: http://www.scholastic.com/Dodea/Module_2/resources/dodea_m2_pa_roledecod.pdf 
written symbols. Phonological awareness is considered the primary phase of reading. It is the recognition and manipulation of phonological units of words: syllables and rhymes. Typically, average children are mature enough to be able to learn decoding letters and the words written by them before they go to school. This phenomenon also underlines the early reading theory (Stanovich, 1986; Juel, 1988) discussed above.

The experiences in most European countries suggest that the poor results in reading comprehension do not stem from the pupils' lack of phonological awareness, but from their poor reading performance. Most Hungarian children can easily distinguish between letters, syllables, and words at an early stage but many of them have problems in understanding the complexity of texts. The main question for educators is therefore not how to develop phonological awareness, but how to improve reading comprehension. Experts should find out whether there is a delay in the development of abstract thinking following the development of phonological awareness, i.e. whether there is a temporal discrepancy between them, or if something is being done inappropriately in education, either before children go to school or after commencing it.

Owing to the fact that from the moment children attend educational institutions they spend more than one-third of their waking hours in them, they gain a significant part of their experiences there. Therefore, the curricula of these institutions should facilitate the procedure of getting to know the world as much as possible. Three-dimensional experiences are essential for pre- and primary school children to improve their memory and facilitate the achievement of the formal operational stage in the case of an average child at around the age of 12 . The more experience they can gain, the more powerful the procedure could be. Unfortunately, gaining physical experience is not at the centre of Hungarian education. Instead, verbal explanations based on deductive reasoning are in the focus, which, as stated above, can result in a lot of drawbacks, as the necessary cognitive skills develop much later. This can lead to manifold problems in and outside educational institutions. Such problems include disciplinary ones, lack of concentration, poor memory, lack of motivation, etc. This practice therefore is especially dangerous among children from families with poor social and educational backgrounds. Inward experiences are the results of the physical ones, and reading comprehension cannot be achieved without inward sensation. One of the priorities in education therefore should be the application of methods by which inward images that later can be connected to everyday experiences could be multiplied, thus developing abstract thinking vital to the future career of the child. Drama activities are the most appropriate means of this procedure. 


\section{Natural Texts}

Working with texts always raises the question of authenticity. In this context, an authentic text is the one that is not created for language teaching purposes. The advantage of these texts is that they are not adjusted to speculative needs and therefore they can be more efficient in language teaching than most inauthentic ones if the content and form of the authentic texts are confirmed by the children's cognitive, social, physical and psychological experience (c.f. Pazonyi, 2008). Artistic texts, such as poems and tales, can be especially effective in developing communicating skills. The more powerful the artistic elements in a text concerning its inward world are, the more suitable it can be for developing listening or reading comprehension; this is the case already towards the end of the pre-operational stage around the age of 5 (and later, in the concrete operational stage), as developed abstract thinking is not needed to comprehend these texts. Folk nursery rhymes are artistically powerful and have survived for long centuries owing to their paradox of "perfect imperfection", which means that, at first sight, they are extremely simple and lack some very basic information which would probably be necessary for an adult to understand their elements thoroughly. Guy Cook argues that no matter how vague nursery rhymes are, "behind the pleasure which children take in rhymes may lie a more serious role in the acquisition of spoken language" (Cook, 2000, p. 26). Whether this argument is true or not, is beyond the scope of this paper, but it cannot be denied that children have enjoyed the same texts of nursery rhymes for centuries, independently from their social and educational background. These texts are often characterised as imperfect and simple. But what does this imperfect simplicity mean? Their imperfection means that they might be fragmentary, and their simplicity refers to their attribute of being organized around one feeling or idea. But they could not have survived for long centuries if they had lacked complexity. Texts, such as those of nursery rhymes or folk tales, and also poems, stories written by different authors, which prove to be lasting for generations of children, can be called "natural".

The terms "nature" and "natural", as basic characteristic features of an approach to language development, were first considered as vital, in the "natural" or "direct language learning method". This method was based on mechanical observations of the baby picking up its mother tongue. Although the subconscious process of language acquisition (cf. Krashen, 1988) was neither mentioned nor considered at the time the "direct method" was established (1900s), it was a significant step in introducing "natural" and "nature" as terms in language education. (Rousseau used the terms two centuries before that, but not in the context of language development.) From the invention of the direct method onwards, natural cognitive processes have almost always been present in language learning methods and techniques. 
"Natural learning" has recently been developed as an alternative approach to traditional education. Without going into detail or commenting on this relatively new approach, the demand for learning methods that are developed in contrast to most institutionalized forms of education cannot be totally ignored, especially being aware of the fact that the traditional school systems in many countries still alienates many children from institutionalized education..$^{10}$ This is especially true in foreign language teaching. Although communication is a natural behaviour for human beings, learning experiences often become obstacles to making progress in learning languages. The main reason for this has its roots in early or primary school education in which children are often forced to operate with abstract notions instead of communicating naturally. In early childhood the focus should be on natural processes, as most children in their developmental stage (till age 12) are not mature enough to understand grammatical systems - not to mention that an average child lacks intrinsic motivation for language learning. However, children communicate happily under circumstances motivating enough.

Simplified, inauthentic texts can be probably more efficient in language development in short-term, but they can hardly stimulate subconscious language processes. According to educational experience the proverb "Easy come, easy go" applies to learning: the less cognitive effort we make, the longer it takes for the information to reach the long-term memory. According to the psychoanalytical approach, the symbolic context of these texts is in accordance with the symbols of human thinking and understanding.

These texts are "natural" because they describe the basic ideas and feelings in archetypical ways in their complexity and their simplicity. They are characterised by binary oppositional compositions, and values of mankind are described in them often in accordance with magic thinking. These are the most important features that have made nursery rhymes, folktales and legends an important part of national cultures, the experience most children come across from an early age and generations pass these pieces on to those that follow them. It was probably not by accident that the British published the first collection of nursery rhymes as early as the $18^{\text {th }}$ century (A Little Pretty Pocket-Book, 1744). From that time onwards, the oral tradition was gradually taken over by the written one, thus preserving archaic forms of the poems and influencing other areas of literature. (English literature is highly influenced by traditional nursery rhymes. Well known examples are Carroll's children's books or the title giving and constructing method in Agatha Christie's books.)

When creating dramatic texts from nursery rhymes, the main question is which elements can be transformed into drama. This is a paradox question in itself, as the word "drama" originally means "action", presuming there is a plot that could be acted out, which is not the case in lyrical poems that express feelings and

10 This phenomenon created partly the demand for alternative schools (cf. Bodonyi, 2012, pp. 15-24). 
ideas but have no plot or characters. Lyrical poems usually have a very complex polyphonic structure of outward- and inward visual, aural elements, time structures, and linguistic elements that can be transformed into drama activities.

\section{A poem dramaturgy method based on poetic texts ${ }^{11}$}

Being a complex method that requires some knowledge of children's literature, poetics, drama education, and methodology of teaching different subjects in primary schools, it can be stated that even the attitude to this kind of holistic attitude to teaching is missing in most of the teacher training curricula in European countries. Still the method can be mastered through some guided practice.

The method is built from different stages that are organised upon one another in a strict order. It is useful to start the introductory drama activities mostly with non-verbal ones to create an atmosphere of trust in which further discussions and acting can take place. These short activities can be followed by a discussion based on guided questions and tasks that facilitate an in-depth comprehension of the text. When teachers or teacher trainees learn how these worksheets can be compiled, they should have some semiotic, poetic knowledge by which a deconstruction of the texts into these tasks can be done. The questions and matching tasks on the sheet are to facilitate an in-depth comprehension of the deep structures: visuals, acoustics, time- space- and language structures of the selected nursery rhymes. The third stage is sharing the findings through group discussions. It is an extremely important and entertaining part of the method guided by the teacher, as at this point the participants realise two facts: 1) decoding texts differ individually to some extent, but 2) there are always signs that signify the same meaning within a context.

The fourth part is transforming the elements of the natural texts into drama activities. At this stage certain drama techniques are presented and practised by which visual elements, shapes, and other different compositions can be acted out. These non-verbal activities are followed by certain acoustic compositions of noises, sounds, and verbal structures. In the fifth part, the compositions of the former stage are built into a dramatic sequence that consists of clearly distinguishable elements. The sixth stage is a discussion again, in which the participants compare the texts with the dramatic presentation to check if the aims of students are clear and whether they are achieved or not.

The content and the order of the stages are the same, no matter whether the session is organised for young children or older ones attending secondary schools, or even teacher trainees mastering the method. Only the types of texts and the emphases on different tasks should be tailored to the different needs.

\footnotetext{
${ }^{11}$ The title of the workshop was: Developing the Inward Eye and the Inward Ear: Poem Dramaturgy.
} 
Teacher trainees certainly need discussions on the method itself apart from learning it by doing.

As stated above, this method involves a very complex combination of drama education, poetics, semiotics, etc., the second phase requires a lot of practice. Especially it is vital to learn how to create worksheets for different age-groups of learners and what could be given to pre-school children who cannot read or write but who have a rich imagination and can understand many things, for example: binary oppositional compositions, such as "sky" and "earth", "light" and "dark", "girl" and boy"; shapes, such as circles, squares; vertical and horizontal directions, and many other elements that these texts abound with. Although primary school children can read, their worksheets should be very similar to those of pre-school children, containing tasks of drawing and colouring, certain compositional exercises and funny problem solving activities to facilitate their drama activities with poems. The method can be used with secondary school children, only the texts should suit their cognitive, psychological, social, and physical needs (cf. the introductory lines about the workshop on poems about the relationship between a child and a mother).

Action rhymes and action songs provide many ideas for dramatization and acting. Any texts with rich polyphony (sounds, rhythm, images, etc.) can offer many more possibilities if creative imagination and understanding of the texts are promoted.

\section{The expected outcome of the poem-dramaturgy method}

Some poems are mini-dramas and are written in the form of dialogues, and therefore they lend themselves to dramatization. On the other hand, some poems are like other nursery rhymes: short and they usually have one simple, but strong emotional theme, which in this case, is more or less clear from the dialogue itself. They have powerful visual and acoustic elements, therefore they also have polyphonic structures which must be dramatized as if they were polyphonic tunes: (1) the outward and inward acoustics; (2) inward images of space, human beings, animals, elements of nature, objects as described in the rhymes; (3) inward time, outward time; and (4) the grammatical structure, all of which are those structural elements that must be performed besides acting out the dialogue. Other nursery rhymes are typical lyrical poems that are organised, as mentioned above, only around one feeling or idea. The verbal elements of the dramatization in these pieces can be transformed mostly from the outward acoustic structure (the one that is physically heard when the poem is recited).

Performing all the existing structural elements (see above) can produce an interesting three dimensional composition of the "dead" paper and printed text, and thus can make children participate in the sequence of actions, and share their otherwise inward worlds of aesthetic response to these poems. These complex 
activities facilitate "learning by doing": children can be part of the literary text and can understand features of it which, if dealing with them in traditional ways, would require fully developed abstract thinking, characteristic of older age groups.

Sharing the experience of the interpretation of artistic texts is one of the priorities of poem dramatization and performance in education. The didactic aim is to design a series of problem solving tasks for children, which can indirectly improve their inward sensation of space, movement and time, and also the recognition of outward and inward acoustic elements and the connections between them. To achieve this we have to clarify beforehand what we mean by space: rooms, nature scenes, streets, houses, etc. Talking about compositions with the help of certain visual aids is necessary. If the method is used with young children simple questions, such as: "What is close to us?"; "What is far from us?"; "How do you know?"; "What is in the centre?"; "What is little, what is big?"; "Are there men or women in the picture?"; "What are they doing?"; "Is anything or anybody moving?"; "How do you know?" have to be asked. Matching activities are also useful for facilitating the interpretations. While concentrating on doing such tasks one unconsciously gets absorbed in the text. The most important aspect is to start everything from physical experience to improve the inward ones. All these are especially vital in a world in which most children's everyday experience is closely connected to the virtual reality.

When dramatizing lyrical poems, both the individual interpretations and the meanings that are shared can be parts of the dramatic interpretations, but the emphasis should always fall on the latter ones. It is more efficient if the tasks are done individually and later the interaction patterns are changed into pair-work and group-work as sharing and discussing experiences are as important as the performances. This procedure can develop children's cognitive, social, and psychological behaviour. It is important that they see how many ideas they share, and also that there are individual differences. This can develop tolerance from an early age.

Poem dramaturgy and the drama activities connected to them belong to those complex, multisensory activities which can develop not only the targeted skills, but the whole personality. The problem with this, as mentioned above, is that the poem-dramaturgy method requires a complex professional expertise of the teacher, which can be acquired through practice. Another difficulty is that many teachers and teacher trainees are afraid of improvisations, without which these methods cannot work. Their reluctance often stems from lacking the necessary creativity, though according to experience, educators in schools providing alternative education are more open to these techniques and ideas.

In Hungarian teacher training programs, the focus is still on the theoretical aspects, and relatively little practical knowledge is provided, though pre- and primary school teacher training programmes involve much more practice than the ones for secondary education. In spite of the relatively conservative 
educational system, alternative schools in Hungary always attract teachers who are willing to master less traditional approaches in education, and parents who insist on a more pupil- and student-friendly environment these schools offer to them.

\section{References}

BODONYI, E. Modern Alternatív iskolák. Budapest: ELTE Eötvös Kiadó, 2012. COOK, G. Language Play, Language Learning. Oxford: Oxford University Press, 2000.

JUEL, C. Learning to Read and Write: A Longitudinal Study of Fifty-Four Children from First Through Fourth Grade. Journal of Educational Psychology, 1988, 80, 437-447.

KRASHEN, S. D. Second Language Acquisition and Second Language Learning. New York: Prentice-Hall International, 1988.

PAZONYI, J. Gondolatok egy korai idegen nyelvoktatási módszer kapcsán. In: Új Pedagógia Szemle. 2008.

PIAGET, J. Selected Works. London: Routledge, 1997.

STANOVICH, K. E. Effects in Reading: Some Consequences of Individual Differences in the Acquisition of Literacy. Reading Research Quarterly, 1986, $21,360-406$. 